\title{
Deleuze e a desformatação da escola
}

Rogério de Souza Teza

\section{Resumo}

Este artigo trata de um assunto cada vez mais presente no debate acadêmico, quer na filosofia, falando-se sobre a obra de Deleuze, quer na pedagogia, que é a superação da padronização no ato do pensar. Há, na filosofia, criação de novos conceitos que são, perse, superadores dos modelos do pensamento ordinário, segundo Deleuze. Seguindo os passos desse original filósofo, buscamos propor uma nova imagem do pensamento a se usar na escola que, em vez da repetição, almeja chegar ao novo.

Palavras-chave: Deleuze - Educação - Pensamento Ordinário - Conceito. 
Em tempos de reorganização das escolas, é importante e salutar retomar um aspecto que ainda escapa às análises menos perspicazes a respeito da educação escolar: ela, na sua versão formalmente instituída, sempre foi, apesar de sóbria, incapaz de escapar ao já pensado. Isto não significa, como poderia parecer, a ineficácia sob o aspecto de não atingir a meta de gerar "gênios" em série, como talvez quisesse algum governante ambicioso. Mas se refere, simplesmente, ao fato de não dar conta de ensinar a pensar de outra forma que não o pensamento ordinário; isto é, de não ir além do regrado e procedimentalizado no raciocínio lógico-dedutivo, pragmático e técnico, no máximo, instrumental.

No livro Bergsonismo, Deleuze resume qual deveria ser, realmente, o ideal da educação: o aluno que deveríamos sonhar saindo dos bancos escolares se parecer figura semelhante ao grande filósofo. Escreve ele que "um grande filósofo [...] cria novos conceitos" que "ultrapassam as dualidades do pensamento ordinário e, ao mesmo tempo, dão às coisas uma verdade nova, uma distribuição nova, um recorte extraordinário” (DELEUZE, I999, p. I25). Pois, Deleuze entrega ao filósofo o ato de criação que gostaríamos de conceder à juventude estudantil e, ao mesmo tempo, vincula essa criação à negação da univocidade da verdade que ainda pauta, sobremaneira, o ensino. Esta é a razão pela qual nunca deveríamos deixar de lado a inclusão da filosofia nos programas curriculares? A resposta é difícil, pois, afinal, "o que é a filosofia?".

Um livro com este nome foi escrito por Deleuze em parceria com Guattari para dar à filosofia, então, seu lugar próprio. Logo na introdução, os autores afirmam que "a Filosofia, mais rigorosamente, é a disciplina que consiste em criar conceitos" (DELEUZE \& GUATTARI, 2OIO, p. II). Esta afirmação, no entanto, nos parece indicar outra direção que não a do título do livro. Mais importante do que dizer qual é a realidade da filosofia, eles nos indicam "o modo de como 'fazer' filosofia" (BIANCO, 2002, p. I96), isto é, de pensar as mesmas coisas de outros modos, de novos modos.

Ressalve-se que o cientista também é criador; ele cria, a partir de referências, aquilo que ocupa a maior parte da carga horária dos jovens alunos em sala de aula. Mas não o é como criador de conceitos; ele não deixa de lado as dualidades, como o verdadeiro e o falso, o ser e o não-ser, a matéria e a forma, o corpo e a mente, muito embora possamos encontrar alguém que diga que a ciência vive dos conceitos. "Para falar a verdade, as ciências, as artes, as filosofias são igualmente criadoras, mesmo se compete apenas à Filosofia criar conceitos no sentido estrito" (DELEUZE \& GUATTARI, 2OIO, p. II). 
Desse modo, o pensamento novo, filosófico, para que seja distintivo, exige não só o criar, mas também o conceito. Por isso, o trecho extraído do Bergsonismo, posto de maneira bastante sumária, é esclarecedor, pois já mostra que a filosofia que buscamos é, de um lado, um recorte, uma distribuição que se dá às coisas; por outro, é criação que vai além dos modelos ordinários.

\section{Ultrapassando o pensamento ordinário}

Para compreender o "novo" que se produz na atividade filosófica, é preciso compreender do que se trata o "pensamento ordinário". Ordinário é o que se move em uma única direção, que respeita uma ordem, que avança conforme a sucessão dos elementos conforme dispostos. Ordinário é também o adjetivo para aquilo que é mais banal, vulgar, para aquilo que é costumeiro e habitual. Não se liga, portanto, a qualquer pensamento, mas à imagem "clássica" do pensamento. Neste sentido, Bianco nos diz que essa imagem é a que "informa e estrutura o pensamento representativo", também chamada de "imagem dogmática do pensamento" (BIANCO, 2002, p. I83).

O pensamento ordinário é o formatado nas escolas, que se limita ao treino, à repetição, à resolução de problemas já solucionados. É um modelo que traz uma narrativa da continuidade ou, no máximo, de rupturas reconciliadas, assumindo uma forma tranquilizante sob suposto domínio da matéria. Entrementes, se caracteriza pela "vontade de verdade do pensador e se concretiza em um método apto a orientar o pensamento e a liberá-lo da possibilidade de erro" (DELEUZE \& GUATTARI, 20I0, p. I83).

O pensamento ordinário é o que se crê capaz de representar o mundo como ele verdadeiramente é. Para tal, ensinava Kant, "não podemos pensar, ou usar nosso entendimento, a não ser segundo certas regras" (KANT, 2003, p. 29). O pensamento ordinário, nas palavras de Deleuze e Guattari, é o que vai nos fornecer as "regras protetoras", ajudar a encadear nossas ideias "segundo um mínimo de regras constantes" (DELEUZE \& GUATTARI, 2OIO, p. 237). Age ele como "uma espécie de 'guarda-sol' que nos protege do caos" (Idem, p. 238). Ao mesmo tempo, contudo, também anula a diferença e, por conseguinte, a novidade. Por isso, é repressor, limitador de inúmeras formas de pensar, redutor das possibilidades de pensamento.

Ir além do pensamento ordinário não significa, porém, abandonar o pensar; muito menos pensar o que está fora, mais além ou distante. Se o pensamento ordinário é representativo, então é este que busca aprimorar a correspondência com o que lhe é externo, voltando-se cada vez mais para 
suas referências, fugindo do caos que é propriamente o pensar. Quando Deleuze e Guattari, em O que éfilosofia?, dão forma a uma nova imagem do pensamento, é justamente através de um mergulho no caos e, por isso, acontece pela instauração de um plano de imanência. O plano de imanência também é uma "imagem do pensamento, a imagem que ele se dá do que significa pensar, fazer uso do pensamento, se orientar no pensamento" (Idem, p. 47). Mas, agora, o pensamento se coloca em uma imagem totalmente nova, que não significa mais buscar o verdadeiro, tal como ocorria no pensamento ordinário:

O primeiro caráter da imagem moderna do pensamento é talvez o de renunciar completamente a esta relação, para considerar que a verdade é somente o que o pensamento cria [...] pensamento é criação, não vontade de verdade, como Nietzsche soube mostrar (DELEUZE \& GUATTARI, p. 67).

\section{Fazendo recortes extraordinários}

Essa nova imagem do pensamento, o plano de imanência, "implica uma espécie de experimentação tateante" (DELEUZE \& GUATTARI, 20IO, p. 52). Traçar um plano de imanência é como fazer um corte no caos, não o organizar ou dispor segundo regras ou acalmá-lo. É a compreensão intuitiva que faz um apelo à criação de conceitos para dar conta de problemas que estavam até então mal colocados. O plano se instaura tomando as determinações do caos. "Cada plano opera uma seleção do que cabe de direito ao pensamento" (Idem, p. 62), sem a submissão servil aos modelos postos.

Os planos de imanência são intuições, elementos diagramáticos que conservam, pelas curvaturas variáveis, os movimentos infinitos do caos; "resta aos conceitos traçar as ordenadas intensivas destes movimentos" (Idem, p. 54). Os conceitos, remetendo às intuições dos planos, suportados por estes, são suas únicas regiões. Criar um conceito é exercer mais um recorte. "Gada conceito corta o acontecimento, o recorta à sua maneira" (Idem, p. 43).

Embora o conceito seja criado por recorte, ele apenas surge como um todo pela articulação, pois se mantém sempre fragmentário para oferecer uma distribuição às coisas, de modo totalmente diferente daquilo a que se prestava a representação ou o conceito kantiano. Porém, o conceito não é criado como associação de ideias distintas, à moda da imagem clássica do pensamento. Mas ocorre por reencadeamentos, por um contorno novo que faz, tornando seus componentes, mesmo fragmentários, inseparáveis, segundo a configuração. 
Assim, pois, "destacar um acontecimento das coisas e dos seres é a tarefa da Filosofia quando cria conceitos" (Idem, p. 42)

Porém, é preciso cuidado para não se supor esse reencadeamento como disposição sucessiva de proposições. Não são as proposições os componentes do conceito. As proposições são correspondentes da relação com estados de coisas, de condições extensionais; o conceito, ao contrário, é intensional, com "s" mesmo, em oposição ao que é extensional. Por isso, não está em ques tão, na criação de conceitos para Deleuze e Guattari, a formação discursiva, já que essa característica se dá entre os sistemas extensivos, da correlação e da semântica referencial. "Daî", afirmam os autores, "decorrem grandes diferenças entre a enunciação fllosófica dos conceitos fragmentários e a enunciação científica das proposições parciais" (Idem, p. 32).

$\mathrm{Na}$ imagem clássica do pensamento, na mesma que estruturou o sistema educacional ainda vigente, a filosofia e a ciência andavam de mãos dadas, e ambas deveriam se apropriar da criação de conceitos. Colocá-los em pés de diferença não significa dar à filosofia status superior que à ciência, nem vice-versa.

Giência e filosofia não são há muito e, na verdade, nem nunca foram a mesma coisa. De acordo com Deleuze e Guattari, "a primeira diferença está na atitude respectiva da Filosofia e da Ciência em relação ao caos" (Idem, p. I39).

É algo bem diferente aquilo que promete a ciência do que promete a filosofia. Enquanto esta busca dar consistência ao caos recolhendo os movimentos infinitos em seus conceitos, aquela almeja o conhecimento, restabelecer função, relações entre os estados das coisas. Faz isso desacelerando as velocidades infinitas do caos para aí constituir suas referências para seus estados de coisas.

No entanto, é a filosofia que imerge diretamente no caos, produz recortes e emerge de lá com suas criações. Por isso, o filósofo não pode ser inimigo do caos. "O caos", conforme escreveram Mostafa e Nova Cruz (2009, p. II9) em comentário sobre Deleuze, "é um mundo todo possível em potência. Por conseguinte, a construção de possibilidades de pensamento também é um todo-aberto, um vazio, uma infinita possibilidade de construção”.

\section{Por uma educação mais filosófica}

As infindáveis possibilidades que o caos guarda em si são o único meio que permite a superação do pensamento ordinário. Pois é lidando diretamente com ele que a filosofia pode erigir seus conceitos e remeter ao cosmos 
mental. Na criação de conceitos, "apenas sob essa condição, que pode sair do caos mental [...] para reabsorvê-lo" (DELEUZE \& GUATTARI, 2OIO, p. 23).

Diferentemente do que sintetiza Kant no auge da modernidade, há, na filosofia, criação de novos conceitos em vez de definições "segundo uso próprio da razão" (KANT, 2003, p. 42). A filosofia é a superação da rigidez dos modelos que suportam o pensamento ordinário, que ainda vigora unanimemente. É na nova imagem do pensamento, filosófica, que se chega ao novo, pois "não imaginamos um grande filósofo do qual não se pudesse dizer: ele mudou o que significa pensar, 'pensou de outra maneira'" (DELEUZE \& GUATTARI, 20IO, p. 63).

Superar a rigidez dos modelos implica mudar tudo que enrijece: desde as relações de poder, do diretor ao aluno, até acabar com a produção em série de provas e das linhas de produção de respostas, de preferência idênticas, em cadeiras enfileiradas. Será preciso que haja espaço livre para o tatear do aluno, que já se transformaria em experimentador implicado pelo plano de imanência. A escola deveria mirar ser caótica tanto quanto possível, pois só o caos guarda em si as possibilidades de superação do pensamento ordinário. Somente se a educação se propuser a não ser a repetição mecânica de conceitos da física, da biologia, da história, da história da filosofia; somente se a educação se propuser a ensinar a pensar com vistas a novos conceitos e fazer, desta maneira, de cada um "um grande filósofo" que, ao menos um pouco, ela cumprirá seu verdadeiro papel. É assim que pode surgir a escola que ensina a construir os novos conceitos e não a repetir os velhos.

Em suma, ensinando a filosofar, ensinando a pensar o extraordinário, a pensar aquilo que foge ao ordinário, ao pré-estabelecido, ao reificado que ela possibilitará a cada aluno fazer a própria ressignificação de suas experiências, concederá a cada um a condição de ser parte do processo de criação do mundo em que vive. É dessa reorganização escolar que poderão sair verdadeiras pessoas que constroem pelo próprio pensamento o modo de organização do próprio saber, e que serão, enfim, capazes de superar o mal-estar desse mundo estandartizado.

\section{Referências bibliográficas}

BIANCO, G. Gilles Deleuze educador: Sobre a pedagogia do conceito. Tradução de Tomaz Tadeu. Educação \& Realidade, vol. 27, nº 2, jul./dez. 2002. 
DELEUZE, G. Bergsonismo. Tradução de Luiz B. L. Orlandi. São Paulo: Editora 34, I999.

DELEUZE, G. \& GUATTARI, F. O que é a filosofia?. $3^{\underline{a}}$ ed. Tradução de Bento Prado Jr. e Alberto Alonso Muñoz. Rio de Janeiro: Editora 34, 2010.

KANT, I. Lógica. $3^{\mathrm{a}}$ ed. Tradução de Guido Antônio de Almeida. Rio de Janeiro: Tempo Brasileiro, 2003.

MOSTAFA, S. P. \& NOVA GRUZ, D. V. Para ler a filosofia de Gilles Deleuze e Félix Guattari. Campinas: Editora Alínea, 2009.

Rogério de Souza Teza - Graduado em Filosofia pela Universidade de São Paulo em 20I5. Mestrando em Filosofia pela Universidade de São Paulo.

rogerio.teza@usp.br 